\title{
Rural Health Analytics
}

\author{
Aditi A. Prabhudesai \\ MCA $3^{\text {rd }}$ year student \\ VESIT, Mumbai University \\ Mumbai
}

\author{
Chaitali Deshpande \\ MCA $3^{\text {rd }}$ year student \\ VESIT, Mumbai University \\ Mumbai
}

\author{
Dhanamma Jagli \\ Asst. Professor \\ VESIT, Mumbai University \\ Mumbai
}

\begin{abstract}
Rural Health Analytics system is a system that holds all the detailed information about health statistics of rural area. As there are various health camps arranged by government as well as private hospitals, this system will show campaign wise data as well as analysis of the campaign data. Such analysis on regular basis will help government to find disease prone areas, preventive measures to be taken and if any special awareness camps are required.

This system provides 'Grampanchayat' wise login in every village. Data of the health camps arranged in that village will be uploaded on system by authorized person. The system on basis of that data will generate statistical figures and data which will help to identify major illness or any particular disease that are more number of people are affected with. This charts and figures can be published in health reports that are generated by grampanchayat on regular basis.

Considering network issues in India, this application works on standalone basis. Data will be uploaded in single system and statistical chart will be generated by system only. Final results generated were transferred to the next level, i.e. to taluka with help of offline mode. As all the data is system generated, it increases the reliability as well as system generated analysis save manual efforts.
\end{abstract}

\section{Keywords}

Grampanchayat, Taluka, Mahanagarpalika

\section{INTRODUCTION}

India is a country where major population stays in rural area. Development is more in urban area compared to rural area. There are many basic systems that are yet to reach to village level. Major problem faced by villages are health issues that cannot be ignored at all.

There is lack of advanced medical facilities as well as lack of knowledge in people regarding health issues. Various health camps are organized by Government and private hospital but there is no data maintenance for the same. This data can help us to analyze health issues as well as disease prone areas and necessary steps could be taken on basis of that.

Rural health analytics is a system that provides authority to a grampanchayat person to maintain the data into system on standalone basis. End user just need to collect report and must enter details of the report in the system. With blood report, he should enter information of campaign that was organized in the village.

The system with help of its predefined function will generate the statistical figures and charts which could be sent to next level authority with help of any offline mode available. Regular generation of such data will help us to maintain proper track of health of villages and effective steps can be taken on the same.

\section{LITERATURE REVIEW}

India is a country of villages. According to 2011 census of India, there are 640867 villages in the country.[1] By referring general facts and figures in news one can easily say that there are no any advanced facilities available in many of the villages. Lack of hygiene is main issue which is cause of many diseases there. Lacking in advanced facilities, people in villages tend to suffer more because of unawareness, preventive measures of that disease. Now-a-days, government in India is taking steps in increase awareness about sanitation, building toilets, etc. Still there are various facts about rural health that one need to worry about. The famous saying people who live in villages are healthier and less affected by disease is nothing but a myth.

\subsection{Observations:}

Diseases caused due to lack of nutrition are: Anemia, low blood count, lack of immunity, malnutrition, low BMR.[5]

- Around $55 \%$ of women in the country have anemia and low blood count. [9]

- Vaccination has also not reached its target as only $65.3 \%$ of children have received full immunization.[9]

- Malnutrition is still prevalent in the country.

- Around $69.5 \%$ of children are suffering from anemia

- $44.7 \%$ girls aged in between 15 to 18 have low BMR.

Most common communicable disease found in India are: Dengue, Malaria, Typhoid, Hepatitis(A,B), Jaundice, Leptospirosis, Diarrheal disease, Amoebiasis, Brucellosis, Hookworm infection, Cholera, Influenza, Filariasis, Tuberculosis.[6]

- Communicable and nutritional diseases cause $\underline{\mathbf{2 9 . 4 1 \%}}$ of deaths.

Common Non communicable diseases are: respiratory diseases, malignant and other neoplasms (cancers) and perinatal conditions (pregnancy complications)

- Non-communicable diseases cause $\underline{\mathbf{4 6 . 9 5 \%}}$ of deaths.

\subsection{Interpretations}

- Disease causing factors are

$$
\begin{gathered}
\text { ○ Lack of Nutrition } \\
\text { ○ Lack of Hygiene }
\end{gathered}
$$

- Different rural parts of the country are suffering with different types of disease.

- Success and effectiveness of healthcare programs are questionable due to gaps in implementation. 
- Healthcare programs do not release any report of observations about current health situation of the particular location.

- Healthcare ministry reports shows data either district wise or state wise, no statistical information about rural health is available.

- To understand and analyse rural health situation and take preventive measures for same, one need to have effective and reliable data reports.

- To reach up to them, one need to have proper plan to reach them with effective facilities required in those areas.

- On basis of data, advanced medication could be provided to each village.

- An effective system that gives statistical information about health scenario can help us to control rural health situations.

\section{WORKING OF SYSTEM}

Rural Health Analytics is a system that holds all data related to medical campaigns that are taken place in that particular village. A single login will be provided to authorize user per grampanchayat. That authorized user will be responsible for the data entered in the system. This user will communicate with the campaigns that are taken place into the village. $\mathrm{He} /$ she will collect all the reports generated by that campaign and will feed it to the system.

Medical campaign details will also be stored in the system on the basis of which further reports will be generated. Each campaign will hold a unique ID, date on which it was organized, number of people visited to that campaign and motive of the campaign.

End user, i.e. authorized person of a grampanchayat will collect all the test reports generated by that campaign. These details will be submitted to the system on the basis of which statistical figures and other related information charts will be generated. These figures will be disease specific, as well as will provide general health check-up analysis chart as well.

Having all such statistical figures, one will be able to identify disease prone areas. On basis on number of people affected by any particular disease, one will be able to study the root causes, preventive measures and awareness camps that are need to be organized to increase awareness amongst the people.

Categorization of such disease further will help us to identify if any village is lacking in sanitation or nutrition or in regular hygiene habit. Once health ministry will able to analyze patterns of the disease in that area, long term preventive measures can be taken care to maintain a healthier environment and better lifestyle.

Fig.1 gives detail idea about working of system in detail. In this figure, User is the end user who actually handles the system and gives access to new authorized user. Authenticated user is the one who is having rights to access and enter information into the system and is responsible about the reliability of data.

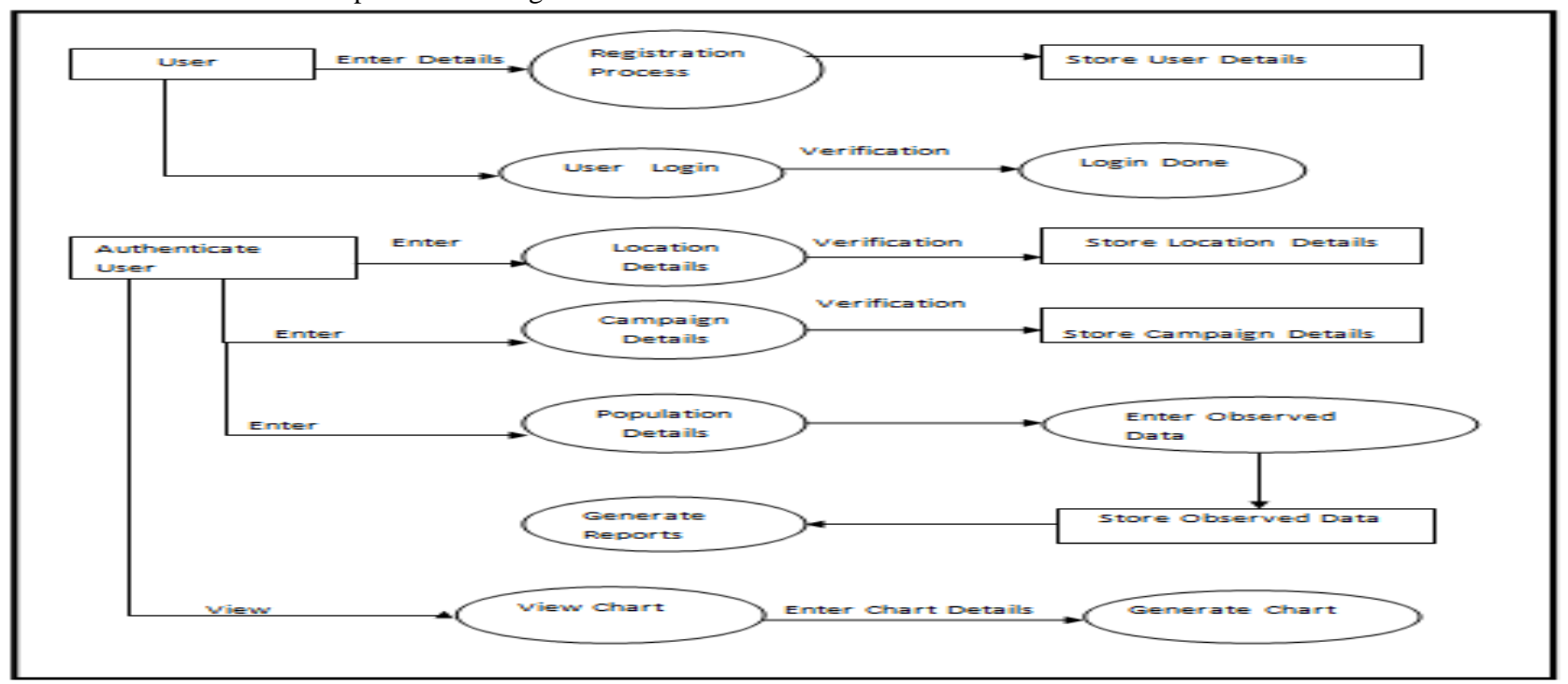

Fig.1) Working of System

\section{HEALTH REPORTS}

The proposed system will generate two types of reports: $1^{\text {st }}$ type of report will be generated campaign wise which will provide us details about campaign. $2^{\text {nd }}$ type of report will give us village wise data that will give us details about all the campaigns held at that particular village. 


\begin{tabular}{|c|c|c|c|c|}
\hline Campaign ID & Name & Age & $\begin{array}{c}\text { Blood } \\
\text { Group }\end{array}$ & Disease \\
\hline 1 & A & 20 & A+ & DENGUE \\
\hline 1 & B & 14 & B + & MALARIA \\
\hline 1 & C & 24 & AB- & MALARIA \\
\hline 1 & D & 59 & B & DENGUE \\
\hline 1 & E & 60 & O+ & DENGUE \\
\hline 1 & F & 47 & B+ & DENGUE \\
\hline 1 & G & 25 & B + & NIL \\
\hline 1 & H & 49 & O+ & NIL \\
\hline 1 & I & 54 & A+ & JAUNDICE \\
\hline 1 & J & 37 & A+ & JAUNDICE \\
\hline 1 & K & 45 & O+ & CHOLERA \\
\hline
\end{tabular}

\section{Campaign Data}

DENGUE MALARIA JAUNDICE

CHOLERA $\square$ NIL

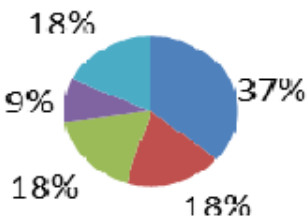

i)Campaign wise data

\begin{tabular}{|c|c|c|c|c|}
\hline $\begin{array}{c}\text { village } \\
\text { Id }\end{array}$ & $\begin{array}{c}\text { Campoign } \\
\text { Id }\end{array}$ & Name & $\begin{array}{l}\text { Blood } \\
\text { Group }\end{array}$ & Diseases \\
\hline 101 & 202 & Aysho Khurenda & $B+$ & Malar ìa \\
\hline 101 & 202 & Nveen Shukla & $\mathrm{B}+$ & Dengui \\
\hline 101 & 202 & Dhana Kulkarni & 0 & Pneumonia \\
\hline 101 & 202 & Utkarsha Shah & 0 & TB \\
\hline 101 & 202 & Shanta Shinde & A & TD \\
\hline 101 & 202 & Vievk More & $A+$ & TB \\
\hline 101 & 202 & Anil Desai & A & Malaria \\
\hline 101 & 203 & Shubhangi More & $\mathrm{AB}+$ & Leptospirosis \\
\hline 101 & 203 & Kishori Dcv & $0+$ & Pncumonia \\
\hline 101 & 201 & Kishan Shelke & O- & Leptospirosis \\
\hline 101 & 201 & Kiran Bind & $\mathrm{B}+$ & TB \\
\hline 101 & 201 & Swara I rıpathı & B- & IB \\
\hline 101 & 201 & Kashmira Dev & $\mathrm{AB}+$ & Cholera \\
\hline 101 & 201 & Suhana Shahane & $\mathrm{AB}+$ & Typhold \\
\hline 101 & 204 & Suren Meheta & 0 & Typhoid \\
\hline 101 & 204 & Diljil Sintla & 0 & Prieurnunid \\
\hline 101 & 204 & Ajmal Ali & $A+$ & TB \\
\hline 101 & 204 & Hari Nage & $A+$ & Malaria \\
\hline 101 & 204 & Himali Cak & $\mathrm{B}+$ & Typhoid \\
\hline
\end{tabular}

\section{Village Data}
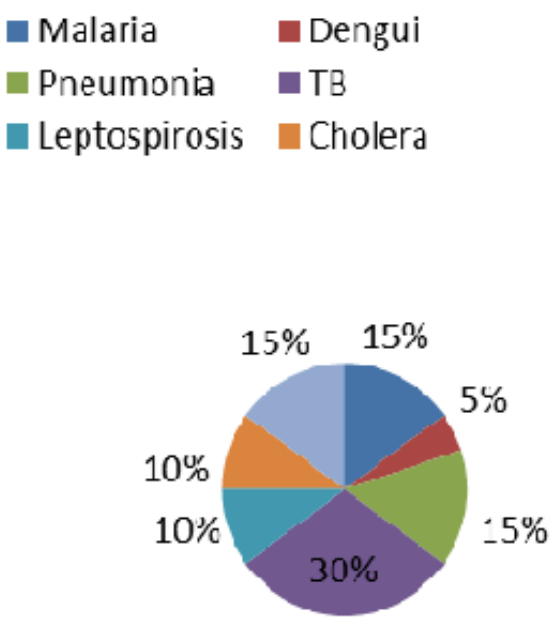

ii) Village wise Report

\section{FLOW OF INFORMATION}

As there are connectivity issues in villages, i.e. most of the villages do not have any internet connection and those that have a connection, suffer from slow internet speed. One can't wait for every village to turn into smart village to implement new system effectively. This system will currently work on single system on standalone basis.

The final result generated will be transferred to next level via offline mode either with help of pen drive or hard disk. This information will be transferred to taluka from grampanchayat, then to mahanagarpalika and then to state government. Sending information via internet after taluka level is possible.

This information can be displayed in health report quarterly or annually. Constant analysis of data through such health reports will help government as well as private hospitals to arrange health camps to treat people of particular disease prone area. Effective steps can be taken when proper information is available.

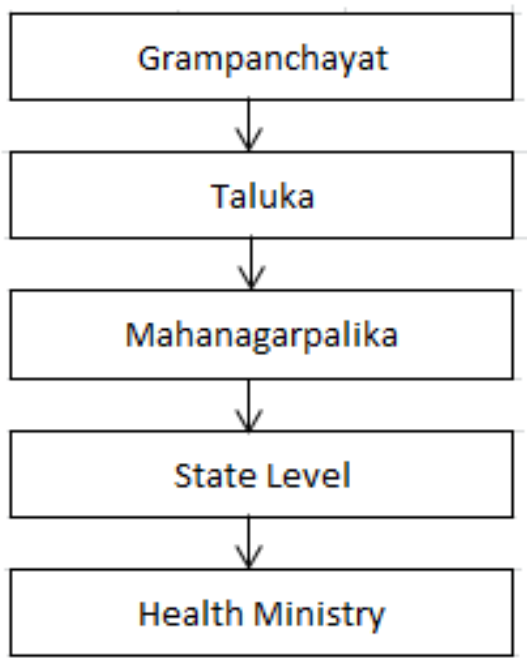

\section{SUGGESSION}

Once issue is identified, next step is to take action to overcome that issue. Effective steps could help to resolve the 
issue permanently. Following are the few suggestions that could be implemented once health issues are identified

1. Awareness camps can be organized by government, private hospitals and NGOs.

2. Sanitization awareness camps can be organized.

3. Healthy rank could be assigned to each village, and top healthy villages will be awarded.

4. Volunteers from each village could be trained to increase and maintain disease awareness.

5. Group of volunteers can constantly update current scenario of health to authority.

6. On basis of data, advanced medication could be provided to each village.

7. Complete nutrition importance lessons will be given from school level.

8. Regular vaccination camps can be arranged in schools.

\section{CONCLUSION}

India is having more number of villages. People there are victims of disease because of either lack of awareness or lack of medication facilities. Clearly, problem faced by rural communities, especially the smallest as well as most isolated, remain elusive. Henceforth, there is need system, which will address to critical situation and problems of health in rural. A proper, system based analyzed data will help to identify sanitization habits, disease prone areas and preventive measures to be taken care of. A proper data analysis will also help us to identify patterns of hygiene habits and health issues on rural areas. Reports on analyzed data will help to discover new threats, issues of health in specific area. Statistical data will help in better analysis and regular annual follow up can be taken to solve all such issues. This system will be the way to address health problems and new threats which may fragile health in rural. This system will keep track of all health records and will help us to make the country healthier from grass root level. This system focused on major attention to rural health and well-being of people in rural and most isolated rural areas. The main aim of system is eradication of diseases in rural in order to improve the rural health.

\section{ACKNOWLEDGMENTS}

The idea of 'Rural Health Analytics' being turned into a vision and now being proposed as research paper was only possible by endless support received from colleagues and professors. Special thanks to Department of MCA, VESIT, Chembur for their acceptance and assistance throughout duration of research. All the support received is appreciated without which the research would have been more difficult. However, any errors or mistake belong to authors and should not affect the reputation of the respected institute.

\section{REFERENCES}

[1] https://en.wikipedia.org/wiki/Health_in_India

[2] www.jssbilaspur.org/rural-health/

[3] http://citeseerx.ist.psu.edu/viewdoc/download?doi=10.1. 1.519.2054\&rep=rep1\&type=pdf

[4] http://www.yourarticlelibrary.com/essay/rural-healthproblems-in-india/34992/

[5] https://www.ncbi.nlm.nih.gov/pmc/articles/PMC5240088

[6] http://www.yourarticlelibrary.com/diseases/top-13common-communicable-diseases-found-in-india/34984/

[7] study.com/academy/lesson/risk-factors-for-contractingcommunicable-diseases.html

[8] http://internal.gramvaani.org/wordpress/?p=1629

[9] https://www.google.co.in/amp/m.indiatoday.in/lite/story/i ndia-health-report/1/544495.html 